This article was downloaded by: [Duke University Medical Center]

On: 19 May 2015, At: 19:41

Publisher: Routledge

Informa Ltd Registered in England and Wales Registered Number: 1072954 Registered office: Mortimer House, 37-41 Mortimer Street, London W1T 3J H, UK

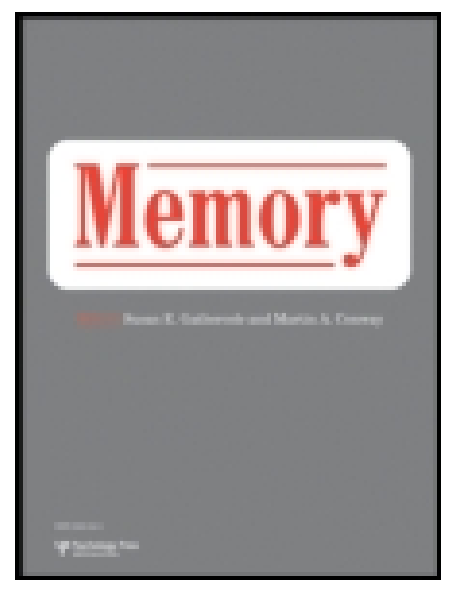

\title{
Memory
}

Publication details, including instructions for authors and subscription information:

http:// www. tandfonline.com/loi/ pmem20

\section{Life-narrative and word-cued autobiographical memories in centenarians: Comparisons with 80-year-old control, depressed, and dementia groups}

\author{
Pia Fromholt ${ }^{a}$, Dorthe Mortensen ${ }^{a}$, Per Torpdahl ${ }^{a}$, Lise Bender ${ }^{a}$, Per Larsen ${ }^{a} \&$ David Rubin \\ b \\ a University of Aarhus, Denmark \\ ${ }^{b}$ Duke University, North Carolina, USA \\ Published online: 21 Oct 2010.
}

To cite this article: Pia Fromholt, Dorthe Mortensen, Per Torpdahl, Lise Bender, Per Larsen \& David Rubin (2003) Life-narrative and word-cued autobiographical memories in centenarians: Comparisons with 80-year-old control, depressed, and dementia groups, Memory, 11:1, 81-88, DOI: 10.1080/741938171

To link to this article: http:// dx. doi.org/ 10.1080/ 741938171

\section{PLEASE SCROLL DOWN FOR ARTICLE}

Taylor \& Francis makes every effort to ensure the accuracy of all the information (the "Content") contained in the publications on our platform. However, Taylor \& Francis, our agents, and our licensors make no representations or warranties whatsoever as to the accuracy, completeness, or suitability for any purpose of the Content. Any opinions and views expressed in this publication are the opinions and views of the authors, and are not the views of or endorsed by Taylor \& Francis. The accuracy of the Content should not be relied upon and should be independently verified with primary sources of information. Taylor and Francis shall not be liable for any losses, actions, claims, proceedings, demands, costs, expenses, damages, and other liabilities whatsoever or howsoever caused arising directly or indirectly in connection with, in relation to or arising out of the use of the Content.

This article may be used for research, teaching, and private study purposes. Any substantial or systematic reproduction, redistribution, reselling, loan, sub-licensing, systematic supply, or distribution in any form to anyone is expressly forbidden. Terms \& Conditions of access and use can be found at http://www.tandfonline.com/page/ terms-and-conditions 


\title{
Life-narrative and word-cued autobiographical memories in centenarians: Comparisons with 80-year-old control, depressed, and dementia groups
}

\author{
Pia Fromholt, Dorthe B. Mortensen, Per Torpdahl, Lise Bender, and Per Larsen \\ University of Aarhus, Denmark \\ David C. Rubin \\ Duke University, North Carolina, USA
}

\begin{abstract}
Centenarians provided autobiographical memories to either a request for a life narrative or a request to produce autobiographical memories to cue words. Both methods produced distributions with childhoodamnesia, reminiscence-bump, and recency components. The life-narrative method produced relatively more bump memories at the expense of recent memories. The life-narrative distributions were similar to those obtained from 80-year-old adults without clinical symptoms and from 80-year-old Alzheimer's dementia and depression patients, except that the centenarians had an additional 20-year period of relatively low recall between the bump and recency components. The centenarians produced more emotionally neutral memories than the other three groups and produced fewer and less detailed memories than the non-clinical 80-year-old sample.
\end{abstract}

Autobiographical memory in centenarians is related to the general development of intellectual functioning through life as well as differential development of specific areas of functioning. It is also related to conditions in old age that might influence autobiographical memory (e.g., dementia and depression). This article provides information on the influence of age, dementia, and depression on autobiographical memory in late life.

The rapidly growing knowledge about cognitive abilities in centenarians suggests that there is a generalised linear decrement in memory functions (Lindenberger \& Baltes, 1997; Poon et al., 1992), but it is not evident how such a decrement in general cognitive abilities affects the more personal and episodic memories that constitute a great part of a life narrative. According to Beard's
(1967) study of centenarians, memories fade either because the referent situations have changed, or the emotional content has changed, or new stimuli interfere with the memories. Beard (1968) tested centenarians' memory for recent and past events, finding no support for the notion that they had better memory for early events and a poorer one for recent events.

Older adults demonstrate a three-component pattern in the distribution of memories across the life span: few memories from childhood (childhood amnesia), a bump in young adulthood followed by a decrease in midlife (a reminiscence bump), and increase in later years (a recency effect) (Conway \& Rubin, 1993; Fromholt \& Larsen, 1991; Rubin 1998, 2000, in press; Rubin \& Schulkind, 1997a, b). The initial description of the bump was based on data from several laboratories

Requests for reprints should be sent to David C. Rubin, Department of Psychological and Brain Sciences, Duke University, Durham, NC, 27708-0086, USA. Email: david.rubin@duke.edu

Thanks are due to Lone Vasegaard and Karen Randhøj-Andersen for their assistance in selecting subjects, Bernard Jeune for taking part in the planning of the study as leader of "The longitudinal study of Danish centenarians", and NIA grant RO1 AG16340 which funded the final preparation of the manuscript for publication after the untimely death of Pia Fromholt. 
reanalysed by Rubin, Wetzler, and Nebes (1986). Since that time there have been consistent findings using the word-cue technique with older adults (Chu \& Downes, 2000; Hyland \& Ackerman, 1988; Jansari \& Parkin, 1996; Rubin \& Schulkind, 1997a, 1997b; see Rybash, 1999, and the subsequent articles in his special issue of the Journal of Adult Development for reviews). Minor differences exist in the shape of the distribution with changes in procedure and subject population, but the bump appears repeatedly, even for individuals (Rubin \& Schulkind, 1997b). The same basic pattern is even found in pathological cases like dementia and depression using a life-narrative instead of a word-cued technique (Fromholt \& Larsen, 1991; Fromholt, Larsen, \& Larsen, 1995).

In 1967 Costa and Kastenbaum published a study in which 276 centenarians reported their earliest memory, the most salient historical event, and their most exciting event. There was a bump for most exciting events, $21 \%$ were dated to ages $0-12$ years, $48 \%$ to ages $13-39$, and only $31 \%$ to the 60 years between 40 and 100 years. Earliest memories and most salient historical events had an earlier peak. The authors concluded that there was more relative interest and richness in telling memories that were dated in the remote than the recent past. This conclusion is consistent with later studies of younger seniors showing that vivid memories tend to be dated rather early in life. Fitzgerald (1988) showed a peak between 11 and 25 years and no trace of a recency increase; similarly, Rubin and Schulkind (1997a) found that important memories from older subjects peaked in their 20s.

Several explanations for the reminiscencebump memories have been suggested. In terms of biological maturation, people are faster and better at simple memory tasks in the bump period; in terms of learning and environment, the bump period is when many culturally defined important events occur, a time of identity formation and the formation of a sense of generation (see Conway \& Pleydell-Pearce, 2000, and Rubin, Rahhal, \& Poon, 1998, for reviews). We know that the environmental factors have an effect beyond maturation, because changes in environment affect the bump (Conway \& Haque, 1999; Schrauf \& Rubin, 1998, 2000).

The purpose of Experiment 1 was to compare a group of non-demented centenarians regarding autobiographical memory with a younger senior group (average age 78), to examine age and cohort effects. In addition, we compare the function of the centenarians with demented (Alzheimer type) and depressed old subjects (both with average ages of 80). These two groups produced similar numbers of memories as the centenarians, allowing differences in the properties of their memories to be examined, with the overall gross level of output being constant. This allows comparisons among "normal ageing", dementia, and depression groups.

\section{EXPERIMENT 1 LIFE NARRATIVE AUTOBIOGRAPHICAL MEMORIES}

\section{Method}

Subjects. Subjects were recruited from a Danish national study on centenarians, "The longitudinal study of Danish centenarians" initiated by South Danish University. We tested 15 centenarians (11 females) from one county who were judged not to be demented, and who accepted to be interviewed. Of these 15 subjects, 6 were living in private homes, 9 in institutions for the elderly.

The subjects were tested with a selection of short cognitive tests (retention of three words, retention of three pictures, word fluency, tactile functions, writing own name, and the clock test). However, due to lack of normative data on this age group and frequent problems with sight and hearing that might interfere with test performance, we did not use these data as strict exclusion criteria, and relied more on the clinical impression of satisfactory mental capacity to complete the interview (all examiners were experienced geropsychologists). One subject was excluded from the sample due to bad test performance and clinical evidence of dementia.

Data from the centenarians were compared with data from a younger group of healthy seniors $(\mathrm{N}=30,18$ females, age range 71-89, mean 78.3 years), a group of depressed subjects $(\mathrm{N}=15,13$ females, age range $72-90$, mean age 80.2 years), and a group of demented subjects (Alzheimer type, $\mathrm{N}=30,25$ females, age range 73-89, mean age 80.5 years). The results from these three comparison groups were collected in earlier investigations using the same procedure (Fromholt \& Larsen, 1991, 1992; Fromholt et al., 1995).

Procedure. All subjects were interviewed by a trained geropsychologist in their own surroundings (private homes or in their private room in 
their institutions). Prior to the interview they were informed that we were studying life experiences of older people and that the data would be treated confidentially. The interview consisted of a 15minute free narrative of life history following the instruction "Tell about the events that have been important in your life". The interviews were taperecorded and later transcribed for analyses. The interviewers made handwritten notes in order to date events immediately after the interview. They were careful not to influence the subjects during the interview by showing special interest in certain issues or life periods, only encouraging remarks to use the allotted time were given. All interviews were scored and checked by all three interviewers following the criteria developed in the previous studies.

\section{Results}

Table 1 provides means for all measures. Comparisons among the three 80-year-old groups appear in Fromholt and Larsen $(1991,1992)$ and Fromholt et al. (1995). Here we add only those analyses that involve data from the centenarians.

Number of memories. There was a significant difference in the number of memories, $F(3,86)=22.36, p<.001$. Pair-wise comparisons (Newman-Keuls tests were used throughout) showed that centenarians did not differ from the depressed or the demented groups, but the healthy 80 -year-old subjects differed from the other groups $(p<.01)$.
Amount of detail. Memories were scored for amount of detailed reported on a 3-point scale: (1) events expressed in one single sentence, (2) events with up to three additional pieces of information, and (3) events with more elaborated contents (see Fromholt \& Larsen, 1991, for further details). Examining Table 1, the same basic pattern is seen for numbers of memories and amount of detail in those memories. There was a significant difference in the amount of details, $F(386)=5.73, p<.01$. Pair-wise comparisons showed that centenarians did not differ from the depressed or the demented groups, but the healthy 80-year-old subjects differed from the other groups $(p<.05)$.

Repetitions of memories. An earlier study (Fromholt \& Larsen, 1991) found that demented subjects had frequent repetitions of memories already told, but neither the centenarians nor any other group did so.

Transitional events. Analysis of events that signified a major change in life (like starting school, getting married, or being widowed) showed significant differences, $F(3,84)=9.05, p<$ .001. Using pair-wise comparisons showed that centenarians differed from the other groups, reporting significantly fewer transitional events ( $p$ $<.01)$.

Emotional valence. The memories were scored with regard to emotional quality-positive, negative, or neutral. Strict criteria were adopted to avoid false attributions of emotionality. All

TABLE 1

Quantitative and qualitative interview variables (means and percentages)

\begin{tabular}{lcccc}
\hline & 100-year & 80-year & Demented & Depressed \\
\hline Memories & & & & \\
$\quad$ Mean & 10.00 & 18.13 & 8.33 & 11.87 \\
$\quad$ Range & $3-20$ & $9-30$ & $0-16$ & $2-21$ \\
Detail score & 2.24 & 2.41 & 2.10 & 2.16 \\
Repetitions & 0.00 & 0.00 & 3.23 & 0.00 \\
Transitions & $13.3 \%$ & $21.4 \%$ & $30.6 \%$ & $19.0 \%$ \\
Emotional valence & & & & \\
$\quad$ Positive & $21.3 \%$ & $29.3 \%$ & $22.8 \%$ & $12.5 \%$ \\
$\quad$ Negative & $7.3 \%$ & $10.7 \%$ & $16.7 \%$ & $27.4 \%$ \\
$\quad$ Neutral & $71.3 \%$ & $60.0 \%$ & $60.6 \%$ & $60.1 \%$ \\
Undated memories & $5.3 \%$ & $8.7 \%$ & $34.1 \%$ & $12.4 \%$ \\
Mean age events & 31.05 & 32.26 & 35.76 & 41.31 \\
\hline
\end{tabular}

Centenarians $(\mathrm{N}=15), 80$-year-old subjects $(\mathrm{N}=30)$, demented subjects $(\mathrm{N}=$ $30)$, and depressed subjects $(\mathrm{N}=15)$. 
memories without specifically expressed emotional quality were scored as neutral (e.g., "I had my 100-year birthday") unless further information expressed positive or negative valence. A 4 (Groups) $\times 3$ (Emotionality) ANOVA showed a significant main effect of emotionality, $F(2,252)=$ $63.39, p<.001$, as well as a significant interaction, $F(6,252)=4.87, p<.01$. Subsequent pair-wise comparisons showed more neutral memories in centenarians than in the other groups $(p<.05)$.

Dating. There was a significant difference in the number of undated memories, $F(3,86)=13.10$ $p<.001$, with the demented subjects producing fewer dated memories than the other groups $(p<$ $.01)$.

Age of events. The mean age of subjects at the events reported (i.e., calculated from birth due to differences in present age) was different in the groups, $F(3,83)=3.81, p<.05$. The depressed subjects had older memories than all other groups $(p<.05)$.

Chronological distribution. The distribution of datable memories across the life span (in 10year intervals) is presented in Figure 1 together with corresponding data from younger seniors, and demented and depressed subjects. As can be seen from Figure 1, the distribution of memories across the life span is similar for all groups, the centenarians differing in that they have 20 additional years of relatively low recall between the bump and the recency portion of the distribution.

Because some of the participants were approximately 80 years old and others 100 years old, the distribution of memories across the life span was analysed statistically from two time perspectives. In the first analysis we used time intervals measured from birth to analyse the first 50 years of life. In the second analysis we used time interval measure from the date of testing to examine more recent memories. First, we calculated the proportion of memories from the first 50 years that occurred in each of the five 10-year intervals from 0 to 50 for all four groups. A 4 (Groups) $\times 5$ (Decades) ANOVA showed a main effect of decade, $F(4,405)=10.55, p<.001$, and a non-significant interaction, $F(12,405)=1.67$. Second, we calculated the proportion of memories that occurred in each of the most recent five 5year intervals. A 4 (Groups) $\times 5$ (Intervals) ANOVA showed a main effect of interval, $F(4,300)=34.56, p<.001$, and a significant interaction, $F(12,300)=2.37, p<.01$. Pair-wise comparisons (Newman-Keuls) showed no significant difference among the groups.

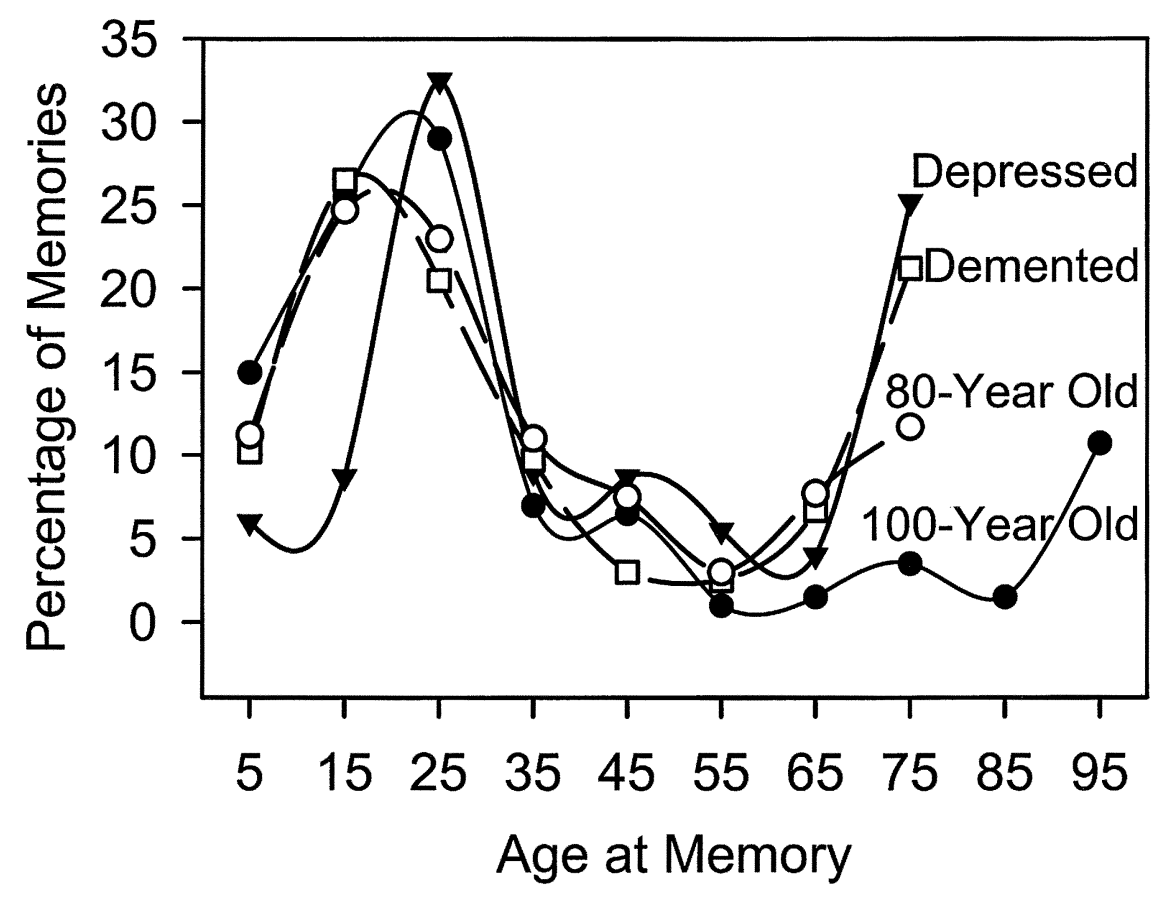

Figure 1. The percentage of life-narrative autobiographical memories that occurred in each decade of life for adults with mean ages of approximately 80 and 100 and for depressed and Alzheimer's patients of mean age 80 . 


\section{EXPERIMENT 2 WORD-CUED AUTOBIOGRAPHICAL MEMORIES}

\section{Method}

Subjects. Subjects were recruited from the same population as Experiment 1. There were 22 centenarians ( 17 females) with a mean age of 100 years, seven months (range 100 years, 0 months to 101 years, nine months) from one county who were judged not to be demented, and who accepted to be interviewed. Of these 22 subjects, 11 were living in private homes, 11 in institutions for the elderly. Two female subjects took part in Experiment 1.

Procedure. All subjects were interviewed by a trained geropsychologist in their own surroundings (private homes or in their private room in their institutions). The sessions were taperecorded and transcribed. Subjects were given 15 cue words (in English translation: cat, cotton, fire, flag, flower, friend, money, morning, nail, picture, road, storm, sugar, ticket, window). For each they were asked to provide a specific, datable autobiographical memory. Testing was done by an experienced geropsychologist. The interviewers made handwritten notes in order to date events immediately after the last word cue was given. They were careful not to influence the subjects during the interview by showing special interest in certain issues or life periods, only encouraging remarks to use the allotted time were given. The word-cue task was at the end of a session that was part of a larger study investigating personality.

\section{Results}

Subjects provided between 0 and 13 dated memories to the 15 cue words (mean 4.91, SD 4.07) for a total of 108 memories. Of these, 20 were from the most recent year. The distribution of memories is shown in Figure 2. The distribution follows closely the pattern shown by the earlier studies with word cues, with a less marked recency effect for memories from the most recent decade. In studies with younger seniors, it is common to have half of the memories coming from the most recent year (Rubin et al., 1986), whereas here only $18 \%$ were from the most recent year. Also shown in Figure 2 are the life-narrative memories from Experiment 1. Comparing distributions, there are fewer bump memories and more recent memories from the word-cue technique. Such direct comparisons of these two methods are rare. The difference may be due to the narrative retrieval

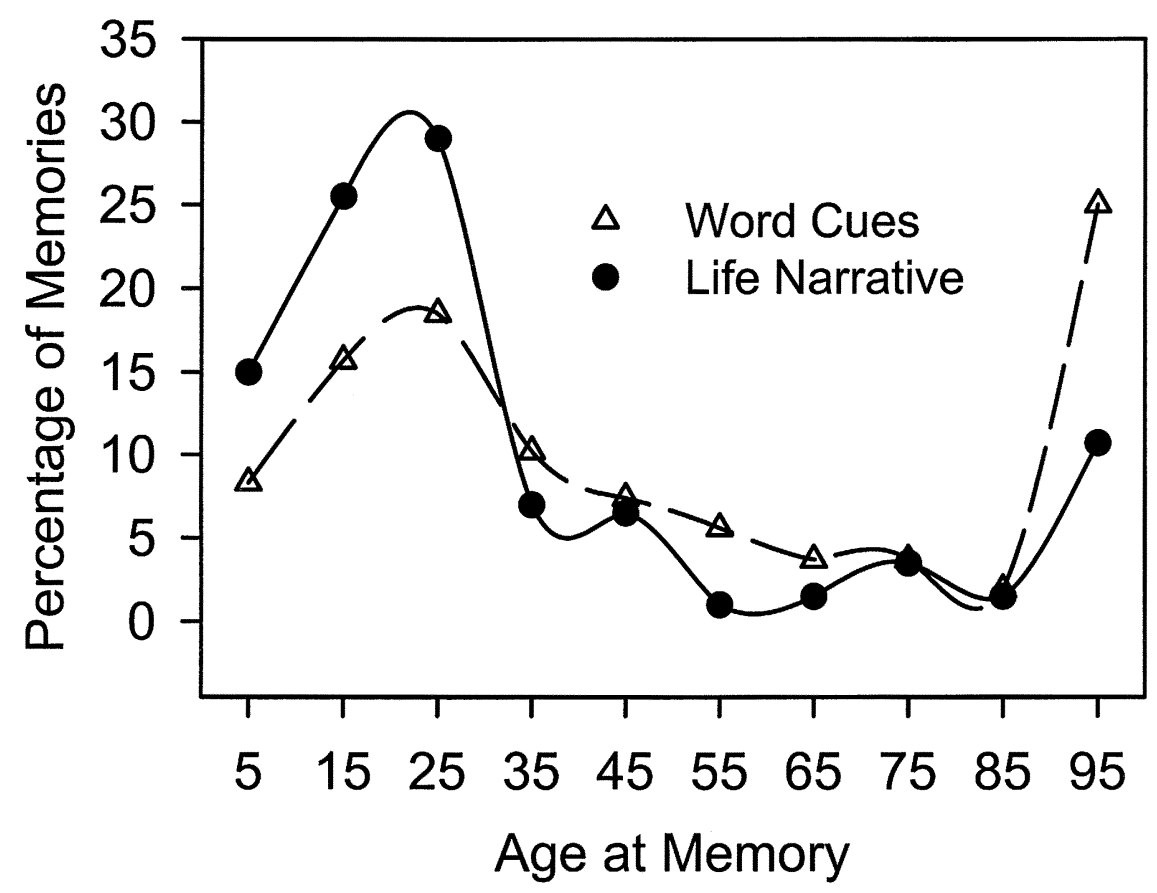

Figure 2. The percentage of life-narrative autobiographical memories that occurred in each decade of life of centenarians using the life-narrative method of Experiment 1 and the word-cued method of Experiment 2. 
focusing more on important or canonical events and the more associative word-cued retrieval of isolated words providing more recent highly accessible recent memories.

\section{AUTOBIOGRAPHICAL MEMORIES OF WORLD WAR II}

Denmark was occupied by Germany from 9 April 1940 to 5 May 1945. It was a time of dramatic changes. The centenarians were in their forties at this time, in comparison with the other groups, who were in their teens or twenties. Thus, the centenarians experienced the occupation after their bump years, the other groups during it. That is, there are cohort as well as age effects that provide us with a natural experiment. Fromholt and Larsen (1992) asked the healthy seniors and dementia patients included in Experiment 1 to tell about important public events that occurred during their lifetime, after they had given their life narratives. Approximately half of the healthy seniors' and threequarters of the demented patients' public event memories were about World War II; all 30 of the healthy seniors and 19 of the 30 demented patients listed at least one such event. We reexamined the life narratives of these groups and the depressed subjects and found that 10 of 30 control subjects, 2 of the 30 demented patients, and 3 of the 15 depressed patients mentioned World War II events in at least one memory. None of the 15 centenarians did so. In Experiment 2 , the centenarians were tested with cue words. These included flag and money, two words likely to cue a memory of a major political change. The word cues produced one World War II memory and four memories from the 1920 reunion of the south of Jutland with Denmark following the World War I, at which time the centenarians were about 20 years old. Although the numbers are small, they are consistent with work by Schuman and colleagues on public events (Schuman \& Rieger, 1992; Schuman \& Scott, 1989) and with work on the distribution of autobiographical memories with older adults. Memories for events as striking as those that occurred during the German occupation of World War II are reported more often if they occur during the bump years. This finding, along with the work of Schuman and his colleagues, suggests an effect of age beyond changes in the environment.

\section{DISCUSSION}

A main finding from the study was that centenarians demonstrated the same chronological distribution of memories across the life span as younger seniors and the two clinical groups. In particular, they exhibited the three components described by Rubin et al. (1986), with an expanded period between the reminiscence bump and the recency effect. The identification of the recency effect is theoretically important. Hypotheses of increased forgetting of recent experiences with ageing cannot be supported with our data. Similarly, a contextual hypothesis predicting that centenarians would have easier access to childhood memories due to their more restricted present life radius and more dependent life style (resembling life in childhood) has to be rejected.

In the life-narrative study of Experiment 1, the mean age of recalled events did not differ in 80year-old subjects and centenarians-both groups had a peak early in the third decade of life, and no difference was found with regard to percentage of datable memories. However, both groups differed from the demented group with respect to the repetition of already told memories-only demented subjects repeated memories, a notion that might have implications for the diagnosis of dementia, and for the differentiation between normal cognitive changes in centenarians and presence of dementia.

The life-narrative memories were analysed with regard to their emotional quality, whether subjects recalled positive, negative, or neutral events. In earlier studies we have shown that depressed and demented subjects had more negative memories than normal controls, and that depressed subjects recovering from the depression had an increased tendency to report neutral memories. In the present study we found that centenarians had more neutral memories than the other groups. This finding has at least two explanations. One possibility is that centenarians develop a more generalised neutral or unconcerned outlook on life (Lerner, 1969), or enter a phase of gerotranscendence as suggested by Thornstam (1996). A second possibility is a generational difference in linguistic expression may play a role, as it is commonly observed that younger generations tend to use more emotional expressions than older ones when they describe events in life-in which case it is difficult to evaluate and compare the personal-emotional significance of an experience. The finding that 
centenarians reported fewer transitional events might be interpreted as support for the first suggestion, indicating that a re-evaluation of the personal significance of life events may have taken place in the centenarian group.

The word-cued memories of Experiment 2 provide a comparison between two methods of cueing autobiographical memories in the same population. As in earlier work, both methods produce a clear bump, with the word-cue method producing a higher proportion of recent memories. Here the same population is used for both methods so the comparison is more precise. A similar effect is noted when the distributions of word-cued and important autobiographical memories are compared. More work is needed to replicate and understand this difference, but a working hypothesis for both effects is that the request for a life-narrative or important memories may invoke a search that involves more of a canonical life story and therefore emphasises the bump period. (Conway \& Pleydell-Pearce, 2000; Habermas \& Bluck, 2000) In contrast, the word cues serve as individual, isolated associative cues, as Galton (1879) intended, evoking whatever memories are most highly accessible to them. These include events from the bump, but also a higher proportion of memories that are highly accessible because they are recent.

Manuscript received 21 January 2002 Manuscript accepted 15 February 2002

\section{REFERENCES}

Beard, B.B. (1967). Social and psychological correlates of residual memory in centenarians. Gerontologist, 7 , $120-124$.

Beard, B.B. (1968). Some characteristics of recent memory in centenarians. Journal of Gerontology, 23, 23-30.

Chu, S., \& Downes, J.J. (2000). Long live Proust: The odour-cued autobiographical memory bump. Cognition, 75, B41-B50.

Costa, P., \& Kastenbaum, R. (1967). Some aspects of memories and ambitions in centenarians. The Journal of Genetic Psychology, 110, 3-16.

Conway, M.A., \& Haque, S. (1999). Overshadowing the reminiscence bump: Memories of a struggle for independence. Journal of Adult Development, 6, 3544.

Conway, M.A., \& Pleydell-Pearce, C.W. (2000). The construction of autobiographical memories in the self-memory system. Psychological Review, 107, 261-268.

Conway, M.A., \& Rubin, D.C. (1993). The structure of autobiographical memory. In A.C. Collins, S.E.
Gathercole, M.A. Conway, \& P.E.M. Morris (Eds.), Theories of memory (pp.103-137). Hove, UK: Lawrence Erlbaum Associates Ltd.

Fitzgerald, J.M. (1988). Vivid memories and the reminiscence phenomenon: The role of self narrative. Human Development, 31, 261-273.

Fromholt, P., \& Larsen, S.F. (1991). Autobiographical memory in normal aging and primary degenerative dementia (Dementia of Alzheimer type). Journal of Gerontology: Psychological Sciences, 3, 85-91.

Fromholt, P., \& Larsen, S.F. (1992).Autobiographical memory and life-history narratives in aging and dementia (Alzheimer type). In M.A. Conway, D.C. Rubin, H. Spinnler, \& W.A. Wagenaar (Eds.), Theoretical perspectives on autobiographical memory (pp.413-426). Dordrecht, The Netherlands: Kluwer.

Fromholt, P., Larsen, P., \& Larsen, S.F. (1995). Effects of late-onset depression and recovery on autobiographical memory. Journal of Gerontology: Psychological Sciences, 2, 74-81.

Galton, F. (1879). Psychometric experiments. Brain, 2, 149-162.

Habermas, T., \& Bluck, S. (2000). Getting a life: The emergency of the life story in adolescence. Psychological Bulletin, 126, 748-469.

Hyland, D.T., \& Ackerman, A.M. (1988). Reminiscence and autobiographical memory in the study of the personal past. Journal of Gerontology: Psychological Sciences, 43, 35-39.

Jansari, A., \& Parkin, A.J. (1996). Things that go bump in your life: Explaining the reminiscence bump in autobiographical memory. Psychology and Aging, $11,85-91$.

Lerner, J. (1969). The centenarians: Some findings and concepts regarding the aged. Journal of the American Geriatric Society, 4, 429-432.

Lindenberger, U., \& Baltes, P.B. (1997). Intellectual functioning in old and very old age: Cross-sectional results from the Berlin aging study. Psychology and Aging, 3, 410-432.

Poon, L.W., Martin, P., Clayton, G.M., Messner, S., Noble, C.A., \& Johnson, M.A. (1992). The influence of cognitive resources on adaptation and old age. International Journal of Aging and Human Development, 1, 31-46.

Rubin, D.C. (1998). Autobiographical memory and aging: Distributions of memories across the lifespan and their implications for survey research. In N. Schwartz, D.C. Park, B. Knauper, \& S. Sudman (Eds.), Cognition, aging, and self-reports (pp.163183). Philadelphia: Psychology Press.

Rubin, D.C. (2000). The distribution of early childhood memories. Memory, 8, 265-269.

Rubin, D.C. (in press). Autobiographical memory across the lifespan. In P. Graf \& N. Ohta (Eds.), Lifespan development of human memory. Cambridge, MA: MIT Press.

Rubin, D.C., Rahhal, T.A., \& Poon, L.W. (1998). Things learned in early adulthood are remembered best. Memory and Cognition, 26, 3-19.

Rubin, D.C., \& Schulkind, M.D. (1997a). Distribution of important and word-cued autobiographical memories in 20, 35, and 70 year-old adults. Psychology and Aging, 12, 524-535. 
Rubin, D.C., \& Schulkind, M.D. (1997b). The distribution of autobiographical memories across the lifespan. Memory and Cognition, 25, 859-866.

Rubin, D.C., Wetzler, S.E., \& Bebes, R.D. (1986). Autobiographical memory across the adult lifespan. In D.C. Rubin (Ed.), Autobiographical memory (pp. 202-221). Cambridge: Cambridge University Press.

Rybash, J.M. (1999). Aging and autobiographical memory: The long and bumpy road. Journal of Adult Development, 6, 1-10.

Schrauf, R.W., \& Rubin, D.C. (1998). Bilingual autobiographical memory in older adult immigrants: A test of cognitive explanations of the reminiscence bump and the linguistic encoding of memories. Journal of Memory and Language, 39, 437-457.
Schrauf, R.W., \& Rubin, D.C. (2000). Identification of internal languages of retrieval: The bilingual encoding of memories for the personal past. Memory \& Cognition, 28, 616-623.

Schuman, H., \& Rieger, C. (1992). Collective memory and collective memories. In M.A. Conway, D.C. Rubin, H. Spinnler, \& W.A. Wagenaar (Eds.), Theoretical perspectives on autobiographical memory (pp.323-336). The Netherlands: Kluwer Academic Publishers.

Schuman, H., \& Scott, J. (1989). Generations and collective memories. American Sociological Review, 54, 359-381.

Thornstam, L. (1996). Gerotranscendence: A theory about maturing into old age. Journal of Aging and Identity, 1, 37-50. 